\title{
ĐÁNH GIÁ CHẤT LƯợNG CUỘC SỐNG NGƯỜI BÊ̂NH UNG THƯ PHỔI DI CĂN NÃO ĐƯợC ĐIỂU TRI XẠ PHẪU GAMMA KNIFE TẠI BỆNH VIỆN K
}

\author{
Nguyễn Thị Thúy Hồng*, Nguyễn Đức Liên*, \\ Phan Thanh Dương*, Nguyễn Thị Hoa Huyền**
}

\section{TÓM TẮT}

Nghiên cứu của chúng tôi nhằm mục tiêu đánh giá chất lượng cuộc sống của người bệnh ung thư phổi di căn não được điều trị xạ phâu Gamma Knife và mô tả một số yếu tố liên quan. Đối tượng và phương pháp nghiên cứu: Nghiên cứu trển 92 người bệnh ung thư phổi di căn não được điêuu tri xa phẫu bằng máy Gamma knife thế hêe Icon từ tháng 7 năm 2020 đến tháng 5 năm 2021. Người bênh được đánh giá về chất lượng cuộc sống trước và sau điều trị 1 tháng bằng bổ công cu của Tổ chức Nghiên cứu và điều tri ung thư Châu Âu EORTC - C30 và EORTC- BN20. Kết quả: Trước điều trị, chất lượng cuộc sống bị ảnh hưởng ở tất cả các khía cạnh bao gôm: hoạt động thể lực, vai trò xã hội, hoàn nhập xã hội, tâm lý cảm xúc, khả năng nhận thức, mệt mỏi, cảm giác đau, mất ngủ, khó thở, rối l̇oan tiếu hóa. Sau 1 tháng điều tri, chất lượng cuộc sống cải thiện rõ rêt với $p<0,05$. Mức độ đau và chỉ số Karnofsky là các yếu tố liên quan đáng kể đến tất cả các chức năng của chất lượng cuộc sống. Kết luận: Chất lượng cuộc sống người bệnh được cải thiện có ý nghĩa $(p<0,05)$ sau điều trị xạ phẩu Gamma Knife.

Tư khóa: ung thư phổi di căn não, gamma knife, chất lượng cuộc sống, EORTC - C30, EORCT - BN20.

\section{SUMMARY \\ QUALITY OF LIFE IN PATIENT WITH BRAIN METASTASIS LUNG CANCER TREATED WITH GAMMA KNIFE AT K HOSPITAL}

Our study aims to evaluate the quality of life of patients with brain metastatic lung cancer who are treated with gamma Knife radiosurgery and describe some related factors. Methods: Studing on 92 patients with brain metastatic lung cancer from July 2020 to May 2021. The patient was treated with radiosurgery using the Icon generation Gamma knife. Patients were assessed for quality of life before and after 1 month of treatment using the toolkit of the European Organization for research and treatment of Cancer EORTC- C30 and EORTC - BN20. Result: Before treatment, quality of life was affected in all aspects, cognitive, ability, fatigue, pain sensation, insomnia, shortness of breath, digestive, disorders. After 1 month of treatement, quality of life improved significantly $(P<0,05)$. Pain severity and the Karnofski

\section{*Bệnh Viện K \\ **Trường Đại học VinUni}

Chịu trách nhiệm chính: Nguyễn Thị Thúy Hồng

Email: hongquang7276@gmail.com

Ngày nhận bài: 14.5.2021

Ngày phản biện khoa học: 5.7.2021

Ngày duyệt bài: 16.7.2021 index were significantly associated with all function of quality of life. Conclusion: the patients quality of life improved significantly $(p<0,05)$ after Gamma Knife radiosurgery.

Keyword: brain metastasis lung cancer, gamma knife, quality of life, EORTC- C30, EORTC - BN20

\section{I. ĐẶT VẤN ĐỀ}

Di căn não là khối u ác tính hay gặp nhất của não, gấp hơn 10 lân ung thư nguyên phát tại não. Khoảng 40-50\% di căn não có nguồn gốc từ ung thư phổi. [1],[2]. Trước đây, di căn não được biết đến là yếu tố tiên lượng xấu, người bệnh suy sụp nhanh với các triệu chứng thân kinh, ảnh hưởng đáng kể đến chất lượng cuộc sống. Nhiều nghiên cứu trên thế giới cho thấy xạ phẫu là một phương pháp điêu trị hiệu quả tổn thương di căn não. Xa phẫu có tỷ lệ kiểm soát tại chỗ cao, giúp cải thiện triệu chứng của người bệnh, kéo dài thời gian sống thêm, trong khi giảm các độc tính trên tế bào lành [3],[4]. Hâu hết các nghiên cứu trong và ngoài nước hiện nay đều tâp trung đánh giá kết quả đáp ứng và̀ sống thêm, chỉ có một vài báo cáo về chất lượng cuộc sống của người bệnh. Do đó, chúng tôi tiến hành nghiên cứu này nhằm mục tiêu đánh giá chất lượng cuộc sống của người bênh ung thư phổi di căn não được điều trị xa phẫu Gamma Knife bằng bộ công cụ của Tổ chức Nghiên cứu và điều trị châu Âu EORTC - C30 và EORTC - BN 20 và mô tả một số yếu tố liên quan.

\section{II. ĐỐl TƯƠNGG VÀ PHƯƠNG PHÁP NGHIÊN CỨU}

2.1 Đối tượng nghiên cứu: Gồm 92 ngườ bệnh ung thư phổi di căn não được điêu trị xạ phẫu Gamma Knife tại Bệnh viện K.

2.1.1 Tiêu chuẩn Iứa chọn: - Được chẩn đoán xác định là ung thư phổi di căn não

- Từ 18 tuổi trở lên.

- Số ổ di căn 1 - 10 ổ, đường kính lớn nhất mỗi ổ $\leq 3 \mathrm{~cm}$

- Có chỉ định xạ phẫu Gamma Knife.

- Không mắc các bệnh lý cấp hoặc mãn tính khác kèm theo.

\subsubsection{Tiêu chuẩn loại trư}

- Di căn các cơ quan khác ngoài não hoặc có đồng thời ung thư nguyên phát thứ hai.

- Đã phẫu thuật lấy u não hoặc xạ toàn não trước đó. 
- Không đủ khả năng hiểu và tự trả lời các câu hỏi trong bộ câu hỏi.

2.2 Địa điểm và thời gian nghiên cứu

- Địa điểm nghiên cứu: Khoa Ngoại Thân Kinh - Bệnh viện $K$

- Thời gian nghiên cứu: từ tháng 7 năm 2020 đến tháng 5 năm 2021

\subsection{Phương pháp nghiên cứu}

2.3.1 Thiêt kếnghiên cứu

- Phương pháp nghiên cứu: nghiên cứu mô tả, tiến cứu.

\subsubsection{Cõ̃ mẫu và chon mẫu}

- Cõ mẫu: thuận tiện. Trong nghiên cứu của chúng tôi được 92 người bệnh

\subsubsection{Các bước tiến hành}

- Thu thập các thông tin người bệnh trước điều trị.

- Đánh giá chất lượng cuộc sống người bệnh trước điêu trị bằng bộ câu hỏi EORTC C-30 và BN 20.

- Đánh giá chất lượng cuộc sống người bệnh sau điều trị 1 tháng bằng bộ câu hỏi EORTC C 30 và $\mathrm{BN} 20$.

2.3.4 Xü lý số liệu. Số liệu được phân tích bằng phân mềm SPSS 20.0. Sau khi hoàn thành thu thập với số liệu đâyy đủ, tác giả tiến hành phân tích kỹ lưỡng.

- Phân tích mô tả: với tân số xuất hiện và tỷ lệ phân trăm, trung bình và độ lệch chuẩn.

- So sánh mối tương quan thống qua sử dụng: T-test, ANOVA nếu phân bố chuẩn. Mức ý nghĩa thống kê lựa chọn cho đề tài này là $p<0,05$.

\section{KẾT QUẢ NGHIÊN CứU}

3.1 Giá trị trung bình của CLCS của EORTC - C30

Bảng 3.1. So sánh giá trị trung bình của CLCS bảng C-30 trước và sau điêu trị 1 tháng

\begin{tabular}{|c|c|c|c|c|}
\hline Lĩnh vực & Khía cạnh sức khỏe & $\begin{array}{c}\text { Trước điêuu trị } \\
\mathbf{X} \pm \text { SD }\end{array}$ & $\begin{array}{c}\text { Sau điều trị 1 tháng } \\
\mathbf{X} \pm \text { SD }\end{array}$ & $\begin{array}{c}\mathbf{P} \\
\text { (T-test) }\end{array}$ \\
\hline $\begin{array}{c}\text { Tình trạng } \\
\text { sức khỏe }\end{array}$ & $\begin{array}{c}\text { Chất lượng cuộc sống } \\
\text { nói chung }\end{array}$ & $21,83 \pm 15,71$ & $42,66 \pm 37,55$ & $<0,001$ \\
\hline \multirow{4}{*}{ Chức năng } & Hoạt động thế lực & $55,87 \pm 29,96$ & $74,93 \pm 23,19$ & $<0,001$ \\
\cline { 2 - 5 } & Vai trò xã hội & $48,37 \pm 28,07$ & $64,86 \pm 33,19$ & $<0,001$ \\
\cline { 2 - 5 } & Hòa nhập xã hội & $50,18 \pm 32,45$ & $66,49 \pm 29,60$ & $<0,001$ \\
\cline { 2 - 5 } & Tâm lý cảm xúc & $50,99 \pm 26,69$ & $74,46 \pm 23,82$ & $<0,001$ \\
\cline { 2 - 5 } & Khả năng nhận thức & $58,97 \pm 27,14$ & $76,0 \pm 23,99$ & $<0,001$ \\
\hline \multirow{3}{*}{$\begin{array}{c}\text { Triếu } \\
\text { chứng }\end{array}$} & Mệt mói & $57,37 \pm 26,42$ & $38,89 \pm 25,44$ & $<0,001$ \\
\cline { 2 - 5 } & Cảm giác đau & $53,44 \pm 30,62$ & $31,34 \pm 23,16$ & $<0,001$ \\
\cline { 2 - 5 } & Mất ngủ & $53,99 \pm 30,40$ & $32,61 \pm 31,63$ & $<0,001$ \\
\cline { 2 - 5 } & Khó thở & $29,71 \pm 26,82$ & $22,10 \pm 25,33$ & 0,003 \\
\cline { 2 - 5 } & Rối loạn tiêu hóa & $23,56 \pm 26,58$ & $14,22 \pm 14,59$ & 0,001 \\
\hline Tài chính & Khó khăn tài chính & $67,03 \pm 34,77$ & $51,81 \pm 34,72$ & $<0,001$ \\
\hline
\end{tabular}

Nhận xét: Tất cả các khía cạnh của chất lượng cuộc sống đều cải thiện sau 1 tháng điều trị.

3.2 Giá trị trung bình của CLCS bảng EORTC - BN20

Bảng 3.2. So sánh giá trị trung bình của CLCS bảng BN-20 trước và sau điều trị 1 tháng.

\begin{tabular}{|c|c|c|c|}
\hline CLCS BN-20 & $\begin{array}{c}\text { Trước điều trị } \\
\mathbf{X} \pm \mathbf{S D}\end{array}$ & $\begin{array}{c}\text { Sau điều trị 1 tháng } \\
\mathbf{X} \pm \text { SD }\end{array}$ & $\begin{array}{c}\text { P } \\
\text { (T-test) }\end{array}$ \\
\hline Sự không chắc chắn về tương lai & $53,89 \pm 24,66$ & $34,96 \pm 24,59$ & $<0,001$ \\
\hline Rối loạn về thị lực & $26,08 \pm 25,06$ & $17,63 \pm 19,50$ & $<0,001$ \\
\hline Mất chức năng vận động & $36,47 \pm 40,29$ & $23,43 \pm 24,79$ & $<0,001$ \\
\hline Giảm giao tiếp & $23,31 \pm 26,72$ & $15,22 \pm 20,49$ & $<0,001$ \\
\hline Đau đâu & $52,17 \pm 28,52$ & $27,90 \pm 28,08$ & $<0,001$ \\
\hline Co giật & $13,04 \pm 24,19$ & $5,43 \pm 15,05$ & $<0,001$ \\
\hline Ngú gà & $30,80 \pm 29,32$ & $23,19 \pm 25,07$ & 0,007 \\
\hline Rụng tóc & $24,28 \pm 30,50$ & $20,65 \pm 29,59$ & 0,234 \\
\hline Ngứa & $29,35 \pm 30,40$ & $24,28 \pm 27,56$ & 0,099 \\
\hline Yếu chân & $27,90 \pm 34,34$ & $19,57 \pm 28,02$ & 0,001 \\
\hline Kiếm soát bàng quang & $28,99 \pm 31,34$ & $21,38 \pm 27,33$ & 0,008 \\
\hline
\end{tabular}

Nhận xét: Các triệu chứng của người bệnh u não đều được giảm sau điêuu trị 1 tháng

3.3. Yếu tố liên quan đến CLCS với QLQ - C30

Bảng 3.3.1 Liên quan yếu tồ thang điểm Karnofski đến chất lượng cuộc sống theo bộ câu hói QLQ-C30 


\begin{tabular}{|c|c|c|c|c|c|c|c|}
\hline \multicolumn{2}{|c|}{ Biến số } & Thể chất & Hoạt động & Nhận thức & Xã hội & Cảm xúc & Tổng quát \\
\hline \multirow{3}{*}{ KPS } & $\geq 90$ & 67,22 & 53,47 & 65,63 & 58,33 & 57,12 & 23,96 \\
\cline { 2 - 8 } & $<90$ & 43,48 & 46,59 & 51,14 & 37,5 & 44,32 & 19,51 \\
\cline { 2 - 8 } & $\mathrm{p}$ & 0,001 & 0,312 & 0,01 & 0,001 & 0,021 & 0,176 \\
\hline
\end{tabular}

Nhận xét: Có sự khác biệt về các chức năng thể chất, nhận thức, xã hội, cảm xúc theo chỉ số toàn trạng.

Bảng 3.3.2 Liên quan yếu tố thang điểm đau đến chât lượng cuộc sống theo bộ câu hỏi $Q L Q-C 30$

\begin{tabular}{|c|c|c|c|c|c|c|c|}
\hline \multicolumn{2}{|c|}{ Biến số } & Thế chất & Hoạt động & Nhận thức & Xã hội & Cảm xúc & Tống quát \\
\hline \multirow{2}{*}{$\begin{array}{c}\text { Mức độ } \\
\text { đau }\end{array}$} & Đau $\leq 5$ & 62,64 & 57,99 & 67,71 & 52,08 & 61,63 & 27,78 \\
\cline { 2 - 8 } & Đau >5 & 48,48 & 41,67 & 48,86 & 44,32 & 39,39 & 15,34 \\
\cline { 2 - 8 } & p & 0,023 & 0,015 & 0,001 & 0,187 & 0,001 & 0,001 \\
\hline
\end{tabular}

Nhận xét: Có sự khác biệt các chỉ số chức năng của chất lượng cuộc sống theo mức độ đau.

3.4. Yếu tố liên quan thang điểm Karnofski đến CLCS với QLQ - BN 20

Bảng 3.4.1 Liên quan yêu tố thang điểm Karnofski đến chất lượng cuộc sống theo bộ câu hói QLQ-BN20.

\begin{tabular}{|c|c|c|c|c|c|}
\hline \multicolumn{2}{|c|}{ Biến số } & Tương lai & Thị lực & Vận động & Giao tiếp \\
\hline \multirow{3}{*}{ KPS } & $\geq 90$ & 50,69 & 18,75 & 21,76 & 13,35 \\
\cline { 2 - 6 } & $<90$ & 57,39 & 34,09 & 52,52 & 33,08 \\
\cline { 2 - 6 } & $p$ & 0,195 & 0,003 & 0,001 & 0,001 \\
\hline
\end{tabular}

Nhận xét: Chỉ số toàn trạng ảnh hưởng đến chất đến chỉ số vận động, giao tiếp, thị lực, và sự không chắc chắn vào tương lai của người bệnh.

Bảng 3.4.2 Liên quan yếu tố thang điểm đau đến chât lượng cuộc sông theo bộ câu hỏi QLQ-BN20

\begin{tabular}{|c|c|c|c|c|c|}
\hline \multicolumn{2}{|c|}{ Biến số } & Tương lai & Thị lực & Vận động & Giao tiếp \\
\hline \multirow{3}{*}{ Mức độ đau } & Đau $\leq 5$ & 43,92 & 18,52 & 32,41 & 23,84 \\
\cline { 2 - 6 } & Đau > 5 & 64,77 & 34,34 & 40,91 & 22,73 \\
\cline { 2 - 6 } & $\mathrm{p}$ & 0,001 & 0,002 & 0,315 & 0,843 \\
\hline
\end{tabular}

Nhận xét: Mức độ đau có ảnh hưởng đến chất lượng cuộc sống của người bệnh

\section{BÀN LUÂNN}

Đánh giá chất lượng cuộc sống theo bộ câu hỏi EORTC- C30, EORTC - BN20 trước và sau điêu trị Gamma knife. Trong nghiên cứu, chúng tôi đánh giá chất lượng cuộc sống theo bộ câu hỏi EORTC QLQ -C30 gồm 30 câu hỏi liên quan đến tình trạng sức khỏe tổng quát, các vấn đề chức năng, các triệu chứng và vấn đề khó khăn tài chính liên quan đến bênh ung thư chung. Thang điểm EORTC- BN20 bổ sung cho thang đo EORTC- C30, được thiết kế để đánh giá chất lượng cuộc sống đặc trưng cho khối u não. Với mỗi chỉ số chức nằng, điểm càng cao chứng tỏ chức năng của người bệnh càng ít bị ảnh hưởng đồng nghĩa với chất lượng cuộc sống tốt hơn. Với mỗi chỉ số về mặt triệu chứng, điểm càng cao chứng tỏ triệu chứng càng trầm trọng và chất lượng cuộc sống bị ảnh hưởng nhiêuu. Theo thang điểm 100, các chỉ số chức năng dưới ngưỡng $80 / 100$, và các chỉ số triệu chứng trên ngưỡng 20/100 được coi là có ảnh hưởng chất lượng cuộc sống. Nghiên cứu của chúng tôi nhận thấy, trước điều trị, chất lượng cuộc sống của người bệnh bị ảnh hưởng ở tất cả các chỉ số chức năng và triệu chứng như hoạt động thể lực, vai trò hoạt động xã hội, hòa nhập xã hội, tâm lý cảm xúc, nhận thức. Tất cả các chỉ số này đều cải thiện đáng kể sau xạ phẫu Gamma Knife 1 tháng $(p<0,001)$. Theo Sildsel Braqstad và cộng sự nghiên cứu về các dự báo về chất lượng cuộc sống và sự sông sót sau phẫu thuật Gamma Knife cho người bệnh ung thư phổi di căn não nghiên cứu trên 44 người bệnh cho thây $60 \%$ có thay đổi về tổng thể CLCS, $15,4 \%$ không thay đổi và $23,1 \%$ có giảm chất lượng cuộc sống [5]. Nghiên cứu của Chen và cộng sự nghiên cứu trên 48 người bệnh về chất lượng cuộc sống bệnh nhân di căn não cho thấy điểm chất lượng cuốc sống sau 1 tháng điều trị xạ toàn não cũng không thay đổi nhiêu, có khả năng đóng vai trò ổn định triệu chứng và ngăn ngừa suy giảm chất lượng cuộc sống [6].

Các yếu tố liên quan đến chất lượng cuộc sống của người bệnh ung thư phổi di căn não. Thang điểm Karnofski và mức độ đau có ảnh hưởng rất nhiều đến chất lượng cuộc sống của người bênh ung thư đã được chứng minh ở nhiều tài liệu nghiên cứu trong nước và quốc tế. Nghiên cứu của Sidsel Bragstad, Chen thì chỉ số toàn trạng Karnofsky có tác dụng dự 
bão mạnh mẽ cho chất lượng cuộc sống và sự ổn định sau xạ phẫu Gamma Knife [5]. Trong nghiên cứu của Nông Văn Dương đánh giá tình trạng đau và chất lượng cuộc sống người bệnh ung thư giai đoạn muộn cũng cho thấy mức độ đau ảnh hưởng đáng kể đên chất lượng cuộc sống của bệnh nhân [7]. Trong nghiên cứu của chúng tôi, chỉ số toàn trạng $\geq 90$ và mức độ đau < 5 có chất lượng cuộc sống tốt hơn đáng kể với sự khác biệt có ý nghĩ̉a thống kê.

\section{KẾT LUÂ̂N}

Chất lượng cuộc sống người bệnh ung thư phổi di căn não cải thiện đáng kể sau điều trị xạ phẫu Gamma Knife. Chỉ số toàn trạng Karnofski và mức độ đau là các yếu tố liên quan đến chất lượng cuộc sống người bệnh.

\section{TÀI LIÊUU THAM KHẢO}

1. J. S. Barnholtz-Sloan, A. E. Sloan, F. G. Davis et al, (2004), Incidence proportions of brain metastases in patients diagnosed (1973 to 2001) in the Metropolitan Detroit Cancer Surveillance System, J Clin Oncol, 22(14), 2865-72.

2. L. J. Schouten, J. Rutten, H. A. Huveneers et al, (2002), Incidence of brain metastases in a cohort of patients with carcinoma of the breast, colon, kidney, and lung and melanoma, Cancer, 94(10), 2698-705.

3. J. P. Sheehan, M. H. Sun, D. Kondziolka et al, (2002), Radiosurgery for non-small cell lung carcinoma metastatic to the brain: long-term outcomes and prognostic factors influencing patient survival time and local tumor control, Neurosurg, 97(6), tr. 1276-81.

4. M. Gerosa, A. Nicolato, R. Foroni et al, (2005) Analysis of long-term outcomes and prognostic factors in patients with non-small cell lung cancer brain metastases treated by gamma knife radiosurgery, J Neurosurg, 102 Suppl, tr. 75-80.

5. S. Bragstad, M. Flatebo, G. K. Natvig et al (2017), Predictors of quality of life and survival following Gamma Knife surgery for lung cancer brain metastases: a prospective study, ] Neurosurg, 129 (1), 71-83.

6. Chen, E., Nguyen, J., Zhang, L. et al, (2012), Quality of life in patients with brain metastases using the EORTC QLQ-BN20 and QLQ-C30, J Radiat Oncol 1, 179-186 https://doi.org/10.1007/s13566-012-0016-0.

7. Nông văn Dương, Bùi Thị Huyên, Trương Thái Sơn và cộng sự, (2018), Đánh giá tình trạng đau và chất lượng cuộc sống ngưới bệnh ung thư giai đoan muốn được chăm sóc giảm nihe tại trung tâm ung bướu Thái Nguyên, Tạp chí Khoà học Điêuu dưỡng, 01 (04), 7 - 13.

\section{TUÂN THỦ ĐIỀU TRI VÀ CHĂM SÓC TƯ VẤN CHO NGƯỜI BÊ̂NH TĂNG HUYẾT ÁP ĐIỀU TRI TẠI BỆNH VIỆN ĐA KHOA KHU VỰC TİNH AN GIANG}

\section{TÓM TẮT.}

Nghiên cứu mô tả cắt ngang kết hợp phân tích thực hiện trên 385 bệnh nhân tại Khoa Khám bệnh, Bệnh viện đa khoa khu vực Àn Giang từ tháng 09/2020 đến tháng 12/2020 trên bệnh nhân THA của BVĐK khu vực An Giang. Mục tiêu (1) là Mô tả thực trạng tuân thủ điều trị của người bệnh THA tại Khoa Khám bệnh, Bệnh viện đa khoa khu vực An Giang và một số yếu tố liên quan. (2)Phân tích thực trạng chăm sóc tư vấn cho NB tại BVĐK khu vực An Giang. Số liệu thu thập được là bệnh án nghiên cứu về tuân thủ điểu trị của người bệnh như nữ chiếm cao hơn nam giới (50,6\% so với 49,4\%), Tuổi trung bình: $66,1 \pm 12,2$; thời gian bị bệnh trung bình $7,8 \pm 5,6$ năm. Có kiến thức tuân thủ điều trị chiếm $78,7 \%$ và chưa có kiến

\footnotetext{
${ }^{1}$ Bệnh viện ĐK khu vực An Giang

${ }^{2}$ Trường $\oplus H$ Thăng Long

Chịu trách nhiệm chính: Lê Thị Bình

Email: lethibinh1818@gamail.com

Ngày nhận bài: 13.5.2021

Ngày phản biện khoa học: 2.7.2021

Ngày duyệt bài: 15.7.2021
}

Nguyễn Như Phượng ${ }^{1}$, Lê Thị Bình ${ }^{2}$

tuân thủ điều trị chiếm $21,3 \%$. Có tuân thủ TH trong điêu trị chiếm $62,9 \%$ và chưa tuân thủ $T H$ chiếm $37,1 \%$; về CS chung cho NB: ở múć tốt chiếm $74,3 \%$ và mức chưa tốt chiếm $25,7 \%$; tư vấn mức tốt cho NB chiếm $70,4 \%$ và mức chưa tốt còn $29,6 \%$. Có sự khác biệt rõ rệt và có ý nghĩa thống kê giữa tuổi > 60 tuổi và $<60$ tuổi với tuân thủ điều trị $(p<0,05)$, giữa trình độ học vấn dưới Trung học phổ thông và đại học (p $<0,05)$; giữa NB không ăn mặn và có ăn mặn ít; giữa không ăn chất béo và ăn ít chất béo; có hút thuốc lá và không hút thuốc lá với tuân thủ điều trị $(p<0,05)$; giữa mắc bệnh trên 10 năm và dưới 5 năm với tuân thư điều trị $(p<0,000)$. Giữa kiến thức chưa tốt và NB có kiến thức tốt với tuân thủ điêu trị $(p<0,000)$; giữa NB chăm sóc chưa tốt và NB được chăm sóc tốt với tuân thủ điêu trị $(p<0,000)$; giữa chưa được tư vân tốt và được tư vấn tốt với tuân thủ điêu trị $(p<0,05)$.

Tư khóa: Tuân thủ điều trị, kiến thức, thực hành, chăm sóc, tư vấn cho bệnh nhân

\section{SUMMARY \\ COMPLIANCE IN TREATMENT AND \\ COUNSELING CARE FOR HYPERTENSIVE \\ PATIENTS TREATED AT THE DEPARTMENT}

